\title{
Lower Intermediate Readers and Their Use of Cognitive and Metacognitive Strategies
}

\author{
Parisa Daftarifard, Parviz Birjandi \\ Islamic Azad University, Science and Research Branch, Tehran, Iran
}

\begin{abstract}
Despite much research done on strategy, there still exist several questions unanswered. Not much research is done to examine lower intermediate English as a Foreign Language (EFL) learners' performance on the reading section of the First Certificate of English exam (FCER) in the post strategy instruction period. The results indicate that learners vary not only in terms of their performance on the FCER, but also on the employed metacognitive strategy. Furthermore, metacognitive strategies are the only predictors that positively predict learners' performance in the FCER.
\end{abstract}

Keywords: reading comprehension, cognitive and metacognitive strategies, first certificate of English

\section{Introduction}

In spite of the tremendous research in the field of applied linguistics on reading comprehension (Abbott, 2006; Grabe, 2009), one of the persistent problems in language testing (LT) has been the nature of reading construct (Duck \& Pearson, 2002). The reason might be due to the fact that different research has depicted this construct differently. This has led the scholars to come up with different conceptualizations of what reading comprehension is (Carrell, 1987; Grabe, 2009, Nist \& Holschuh, 2000).

To unravel the mystery of reading comprehension ability, scholars have attempted to clear up the possible underlying processes English as Foreign Language (EFL) readers at different English proficiency levels might go through to answer reading items. Caldwell and Leslie (2010) used think-aloud protocol analysis to investigate the nature of reading construct. Cohen and Upton (2007) examined different strategies both native and nonnative speakers used to answer the reading section of the TOEFL test. All these enquiries have revealed that the nature of reading comprehension differed across different groups. McGuire and Yewchuk (1996), for example, studied four gifted upper elementary students with reading problems found that these students used evaluation, paraphrasing, and regulation of metacognitive strategies effectively; however, what they significantly showed was individual differences in using strategies. Anderson, Bachman, Perkins, and Cohen (1991) found that there was a significant relationship among question types, learners' performance on reading test and the reading strategy they used. Elsewhere, O’Malley and Chamot (1990) found out that the nature of learners' strategy use influenced their way they performed in a given task.

Parisa Daftarifard, lecturer, Ph.D. candidate, Department of Foreign Languages and Literature, Science and Research Branch, Islamic Azad University, Tehran, Iran. (pdaftaryfard@srbiau.ac.ir.)

Parviz Birjandi, professor, Ph.D., Department of Foreign Languages and Literature, Science and Research Branch, Islamic Azad University, Tehran, Iran. (Corresponding author: pbirjand@srbiau.ac.ir.) 


\section{Reading Comprehension and Strategy}

There is no single way to explain reading comprehension (Grabe, 2009). Reading comprehension issues have been discussed from different perspectives including "metacognitive theory" (Nist \& Holschuh, 2000), "schema theory" (Alderson, 2000; Brown \& Yule, 1989), "knowledge theory" (Nist \& Holschuh, 2000), and "text structure theory" (Halliday \& Hasan, 1984; Carrell, 1990). Khalifa and Weir (2009) delineated that there were three possible ways to explain reading comprehension as (1) the factorial approach which indicates that reading is a multi-divisible construct (Grabe, 2009); (2) the skill approach which explains the nature of reading comprehension based on the respondents' behavior; and (3) the cognitive processing model that depicts reading comprehension in terms of different levels of representations. The reading section of the new FCER has adopted both cognitive and skill approach to reading comprehension (Khalifa \& Weir, 2009).

The FCER test is constructed to measure learners' competency at upper intermediate proficiency level. In this test, three types of reading comprehension are measured (Khalifa \& Weir, 2009) as comprehending across sentences, following the organization of the text, and searching reading. The first part measures learners' ability to find main ideas, writers' attitude, tone, purpose, and opinion, to understand the propositional meaning, and text organization features. The second part taps on learners' ability to follow text structure such as cause-effect, comparison-contrast, and similar relationships (Grabe, 2009). Finally the last part measures readers' ability to scan the multiple texts. Scanning is a form-based perceptual recognition process, like looking for a date; no semantic processing is required during such a search, whereas skimming is a more meaning-based activity which involves a slower processing rate and requires stopping in places to semantically process words, phrases, and clauses (Grabe, 2009).

To unveil what processes learners may go through to answer the FCER items, we probe into learners' use of cognitive and metacognitive strategies. Learning strategy refers to any action that learners take to solve a learning problem; it includes cognitive, metacognitive, and affective strategies (Oxford, 1990). Research indicates qualitative and quantitative differences between competent and poor readers (Grenfell \& Macaro, 2007; Macaro, 2001; O’Malley \& Chamot, 1990; Takac, 2008). Oxford (1990) believes that successful use of strategy highly hinges on learners' flexibility. Moreover, Anderson, Bachman, Perkins, and Cohen (1991) found that there was a relationship between strategy use and question type. They found that learners made use of skimming, paraphrasing, guessing, and elimination when they answered difficult items.

Despite much research done on strategies, there still remain many questions unanswered. Little research is done to examine lower intermediate EFL learners' performance on the reading section of the FCE exam. To this end, this research addresses the following questions:

(1) Is there any significant relationship between different types of strategy and the FCER?

(2) To what extent can EFL learners' use of strategies predict their performance on the FCER?

(3) Is there any significant difference between poor and good readers' use of reading strategies?

\section{Method}

This study followed ex-post facto design through which the data of 144 EFL learners attending a preparatory course for reading section of the FCE exam were gathered. The learners (47 male and 97 female) were studying English related majors at Islamic Azad University and aged between 18 and 35 years old. Based on their score on the Oxford Placement Test (OPT), they were estimated to be at the lower intermediate levels scores ranging from 24 to 34 on the OPT. 


\section{Instruments}

Three instruments were used in this study as (1) the Oxford Placement Test to estimate participants' English proficiency level; (2) reading section of the FCE exam to estimate their reading competency; and (3) Cognitive and Metacognitive Reading Questionnaire to elicit their use of reading strategy. The 60 item OPT test measures participants' reading, grammar, and vocabulary through three parts. The Cronbach Alpha yielded the alpha of 0.70 for this instrument.

The second instrument was FCER which measures reading ability through three tasks with the total length of 2,000 words. The first task consists of eight multiple choice questions aiming at measuring participants' global careful reading. The second part is composed of a text with seven sentences removed and placed in a scrambled order together. The last part comprises of several short texts preceded by 15 multiple matching questions. The test lasted 90 minutes. Two items (6 and 21) were omitted from the final analysis because they were insignificantly correlated with the FCER total score; the item-total correlation ranged from -0.24 to 0.573 at the significant level of 0.05. After omission, the Cronbach Alpha yielded an alpha of 0.81 for this test.

The last instrument was Cognitive and Metacognitive Reading Questionnaire (CMR-Q) with 27 five point Likert type questions. The questionnaire is taken from Phakiti (2003), and measures two types of reading strategies of cognitive and metacognitive, each with two levels. From among 27 questions in this questionnaire (1) five questions $(2,6,7,8,9)$ measure Comprehending cognitive strategy; (2) four questions $(4,5,20,28)$ measure Retrieval cognitive strategy; (3) 11 items (14, 16, 18, 22, 21, 24, 25, 29, 31, 32, 33) measure Planning metacognitive strategies; and (4) finally seven questions (15, 17, 19, 23, 26, 27, 30) measure Monitoring metacognitive strategy. Cronbach Alpha analysis yielded an alpha of 0.90 .

\section{Results}

Reading strategies and the FCER test. The results of Pearson correlation coefficient indicated that none of Cognitive strategies were significantly correlated with FCE, whereas FCE is significantly correlated with Planning metacognitive strategy $(\mathrm{r}=0.287, \mathrm{p}<0.05)$ and Monitoring metacognitive strategy $(\mathrm{r}=0.27, \mathrm{p}<$ 0.05). This indicates that students' metacognitive abilities change through reading classroom, although this seems not to happen for these students' cognitive skills.

Whether strategy can predict performance on the FCER exam. The results of multiple-regression using backward method revealed that two strategies of comprehension and planning predict 13.5 percent of the reading section of the FCE exam, $R^{2}=0.135, \mathrm{~F}(2,141)=11.011, \mathrm{p}<0.05$. The total $\mathrm{R}$ reported in this analysis is 0.368 and the $\mathrm{R}$ Square is 0.135 . Furthermore, the results indicated that Comprehension cognitive strategy $(\mathrm{t}$ $(137)=-2.93, p<0.05)$ and Planning metacognitive strategy $(\mathrm{t}(137)=4.433, \mathrm{p}<0.05)$ were significant predictors of learners' success in the reading section of the FCE exam. The standardized Beta values for these two predictors (Comprehension $\beta=-0.244$, Planning $\beta=0.368$ ) were significant. However, the negative Beta indicates that students misused comprehension cognitive strategy.

A close look at the questions 2, 6, 7, 8, and 9, which form comprehension strategy, indicates that Comprehension strategy in Phakiti's (2003) questionnaire is limited to translation (question 1), inferencing the text irrespective of word knowledge (question 6), grasping the main idea through skimming and scanning (question 7), finding possible relationship between text and reading question (question 8), and using prior knowledge (question 9). As the participants in this study were lower intermediate learners participating in the FCE preparation class, the finding is not surprising. However, the regression analysis revealed that planning 
metacognitive strategy was a positive predictor of learners' performance in the reading section of the FCE. This means that with better planning strategy, EFL learners' performances on the reading section of the FCE improved.

Poor and good readers' use of strategies. Cluster analysis was used to categorize learners into two groups of poor $(M=9.22, S D=3.16)$ and $\operatorname{good}(M=19.16, S D=3.10)$ readers. The results of one-way Analysis of Variance (ANOVA) indicated that two groups were significantly different from each other in terms of their score in the FCER exam, $\mathrm{F}(1,143)=327.47, \mathrm{p}<0.05$.

Four independent $t$-tests were run on the four measures of CMR-Q Composites. The results revealed that Poor $(\mathrm{M}=36.79, \mathrm{SD}=6.5)$ and $\operatorname{good}(\mathrm{M}=41.26, \mathrm{SD}=7.8)$ readers were significantly different on their score in Planning metacognitive strategy; $\mathrm{t}(85.4)=-3.43, \mathrm{p}<0.05$. Moreover, there was a significant difference in the scores of Monitoring metacognitive strategy for poor $(M=23.71, S D=4.1)$ and $\operatorname{good}(M=26.26, S D=4.4)$ readers; $\mathrm{t}(142)=-3.41, \mathrm{p}<0.05$. These results indicated that good readers employed metacognitive strategies significantly more than poor readers.

\section{Conclusion}

This study was to investigate the relationship between ELF lower intermediate learners' performance (good versus poor performance) on FCER and cognitive and metacognitive strategies they used during test-taking. The results revealed that only metacognitive strategies were correlated with FCER. As the FCER test and the questionnaire were given at the end of the preparatory course for the FCER exam, the result was not surprising. It was expected that students' metacognitive abilities would change through reading classroom; this seemed not to happen for this students' cognitive skills, though. This is in line with Phakiti's (2003) research which reported a positive relationship between metacognitive strategies with the reading test performance although the correlation he found was not high. The reason for lack of correlation between cognitive and reading test performance in this study might be due to the fact that the participants in this study were at the B1 English proficiency level, whereas the FCER exam addresses upper intermediate learners.

Another finding of this study was that Comprehension cognitive strategy and Planning metacognitive strategy predicted learners' performance in the FCER. A surprising point was that Comprehension Beta was negative. This indicated that students misused Comprehension cognitive strategy. This is in line with research that indicated low proficient language learners could not properly make use of cognitive strategies (Caldwell \& Leslie, 2010; Wade, 1990). Wade (1990) found that good readers were more meaning-based and used inferences more properly, whereas poor readers resorted to prior knowledge and made hypothesis for every segment of the text. Elsewhere, Caldwell and Leslie (2010) found that most readers with high scores on question and few inferences in their recall have resorted to paraphrasing the text instead of inferencing and building mental model of the text.

And finally the results indicated that good readers' uses of Planning and Monitoring metacognitive strategies were significantly better than those of poor readers. This is in line with Purpura's (1998) studies. Purpura (1998) explored the interrelationship between learners' performance on L2 (second language) test (reading comprehension and grammar) and their cognitive and metacognitive strategy use, using exploratory factor analysis and structural equation modeling. The result of 1,382 participants taking both questionnaire (80 items) and a standardized language test ( 70 items) indicated poor readers used retrieving metacognitive strategies more, whereas good readers used other metacognitive strategies. 


\section{References}

Abbott, M. (2006). ESL reading strategies: Differences in Arabic and Mandarin speaker test performance. Language Learning, $56(4), 633-670$.

Alderson, J. C. (2000). Assessing reading. Cambridge: CUP.

Anderson, N. J., Bachman, L., Perkins, K., \& Cohen, A. (1991). An exploratory study into the construct validity of a reading comprehension test: Triangulation of data sources. Language Testing, 8(1), 41-66.

Brown, G., \& Yule, G. (1989). Discourse analysis (8th ed.). Cambridge: Cambridge University Press.

Carrell, P. L. (1987). Text as interaction: Some implications of text analysis and reading research for ESL composition. In U. Connor and R. B. Kaplan (Eds.), Writing across languages analysis of L2 text (pp. 47-56). Longman: Addison-Wesley Publishing Company.

Carrell, P. L. (1990). Awareness of text structure: Effects on recall. Language Learning, 42(1), 1-20.

Caldwell, J., \& Leslie, L. (2010). Thinking aloud in expository text: Processes and outcomes. Journal of Literacy Research, 42, 308-410.

Cohen, A. D., \& Upton, T. A. (2007). I want to go back to the text: Response strategies on the reading subtest of the new TOEFL. Language Testing, 24(2), 209-250. doi: 10.1177/0265532207076364

Duck, N. K., \& Pearson, P. D. (2002). Effective practices for developing reading comprehension. In A.E. Farstup and S. J. Samuels (Eds.), What research has to say about reading instruction (pp. 205-242). Newark, DE: International Reading Association.

Grenfell, M., \& Macaro, E. (2007). Claims and critiques. In A. D. Cohen and E. Macaro (Eds.), Language learner strategies: Thirty years of research and practice (pp. 9-28). Oxford: OUP.

Grabe, W. (2009). Reading in a second language: Moving from theory to practice. New York: Cambridge University Press.

Halliday, M. A., \& Hasan, R. (1984). Cohesion in English. London: Longman.

Khalifa, H., \& Weir, C. J. (2009). Examining reading: Research and practice in assessing second language reading. Cambridge: UCLES/CUP.

Nist, S., \& Holschuh, J. L. (2000). Comprehension strategies at the college level. In R. F. Flippo and D. C. Caverly (Eds.), Handbook of college reading and study strategy research (pp.75-104). Longman: Lawrence Erlbaum Associates.

Macaro, E. (2001). Analyzing student teachers' codeswitching in foreign language classroom: Theories and decision making. The Modern Language Journal, 85, 531-548.

McGuire, K. L., \& Yewchuk, C. (1996). Use of metacognitive reading strategies by gifted learning disabled students: An exploratory study. Journal for the Education of the Gifted, 19, 293-314.

O’Malley, J. M., \& Chamot, A. U. (1990). Learning strategies in second language acquisition. Cambridge: CUP.

Oxford, R. L. (1990). Language learning strategies: What every teacher should know. MA: Heinle.

Phakiti, A. (2003). A closer look at the relationship of cognitive and metacognitive strategy use to EFL reading achievement test performance. Language Testing, 20(1), 26-56.

Purpura, J. E. (1998). Investigating the effects of strategy use and second language test performance with high and low ability test takes: A structural equation modeling approach. Language Testing, 15(3), 333-379.

Takac, V. P. (2008). Vocabulary learning strategies and foreign language acquisition. Toronto: Multilingual Matters LTD.

Wade, S. (1990). Using think aloud to assess comprehension. The Reading Teacher, 43(7), 442-451. 